\title{
Predictive value for coeliac disease of antibodies to gliadin, endomysium, and jejunum in patients attending for jejunal biopsy
}

\author{
Stanley A McMillan, David J Haughton, J Dennis Biggart, J David Edgar, Kenneth G Porter, \\ Thomas A McNeill
}

\begin{abstract}
Objective-To investigate the extent to which the detection of antibodies to gliadin, endomysium, and jejunum predicts the eventual diagnosis of coeliac disease according to the revised ESPGAN diagnostic criteria in a group of patients in whom there is a high suspicion of coeliac disease.
\end{abstract}

Design-Clinical assessment and laboratory analysis of patients with suspected coeliac disease.

Setting-Gastroenterology department of teaching hospital.

Patients-96 adults with suspected coeliac disease attending for jejunal biopsy.

Main outcome measures-Diagnosis of coeliac disease with the revised criteria of the European Society of Paediatric Gastroenterology and Nutrition in patients with and without antibodies associated with coeliac disease.

Results -28 patients had a clinical diagnosis of coeliac disease, seven of other gastrointestinal diseases, and 12 of miscellaneous diseases; 49 had no diagnosis. Gliadin IgA detected by ELISA was found in all patients with coeliac disease and none of those without, giving a sensitivity, specificity, positive and negative predictive values, and predictive efficiency of $100 \%$ for diagnosing coeliac disease within the group. Endomysial IgA was found in 25 $(89 \%)$ patients with coeliac disease and jejunal IgA in 21 (75\%); neither IgA was found in patients without coeliac disease.

Conclusion-Detection of gliadin IgA by ELISA and to a lesser extent the endomysial IgA should allow better selection of patients for jejunal biopsy and thus make diagnosing coeliac disease simpler and more efficient.

Regional Immunology Laboratory, Belfast City Hospital, Belfast BT9 7AD Stanley A McMillan, PHD, principal clinical scientist David J Haughton, BSC medical laboratory scientific officer

J David Edgar, MRCP, registrar in immunology Thomas A McNeill, FRCPATH, consultant immunologist

Belfast City Hospital and Queen's University, Belfast J Dennis Biggart, FRCPATH, consultant histopathologist Kenneth G Porter, MD, consultant gastroenterologist

Correspondence and requests for reprints to: Dr McMillan.

$B M \mathcal{F} 1991 ; 303: 1163-5$

\section{Introduction}

In 1979 the European Society of Paediatric Gastroenterology and Nutrition recommended criteria for diagnosing coeliac disease.' Since then the accumulated knowledge of the clinical, pathological, and laboratory manifestations and of the practical aspects of management of this condition have led many to adopt a more flexible approach to diagnosis, ${ }^{2}$ and arising from this the society has recently revised its recommended criteria. ${ }^{3}$ These require characteristic small intestinal mucosal histology while the patient is eating normal amounts of gluten and unequivocal clinical remission after exclusion of gluten from the diet.

Much effort has been expended in attempting to develop reliable non-invasive means of diagnosing or at least simplifying the diagnosis of coeliac disease. Methods are also needed to chart dietary compliance and response without the need for repeated jejunal biopsies as well as for avoiding other troublesome and potentially harmful requirements of the original diagnostic criteria. Attempts to develop serological tests have been prominent, but their sensitivities and speci- ficities have varied. ${ }^{4}$ Circulating antibodies to gliadin, endomysium, and jejunum ${ }^{5.8}$ and IgA subclass determination of gliadin antibodies ${ }^{9}{ }^{10}$ have been the focus of attention in recent years. We investigated the extent to which detection of these antibodies predicted the eventual diagnosis of coeliac or other disease according to the revised diagnostic criteria in an adult population preselected for a high index of suspicion of coeliac disease.

\section{Patients and methods}

We studied 96 consecutive patients ( 60 females, 36 males) who had been referred during 1988 by their family practitioners to a hospital gastroenterology clinic and in whom due to clinical suspicion of coeliac disease it was thought appropriate to perform a jejunal biopsy. These patients had various presenting symptoms, including diarrhoea, tiredness, vomiting, weight loss, abdominal pain, and short stature. The mean age of the group at the time of biopsy was 40 years (range 16-80 years) and none of the patients had been previously investigated for coeliac disease or other specific cause of malabsorption or was taking a gluten free diet. The jejunal biopsy specimens were obtained by using a Crosby capsule "muzzle loaded" on a gastroscope and were examined histologically by one of us (JDB). A blood sample was taken at time of biopsy and stored at $-70^{\circ} \mathrm{C}$ until tested for antibodies associated with coeliac disease.

The patients' records were reviewed by one of us (JDE) during the three months August to October 1990 and the revised criteria for diagnosis of coeliac disease applied. ${ }^{3}$ Sera from all the patients with abnormal villous histology were assayed for total IgA to identify those with selective IgA deficiency; no such patients were detected.

The stored sera were tested for the following antibodies associated with coeliac disease during June to August 1990. Gliadin IgA and IgG were detected by indirect immunofluorescence and by enzyme linked immunosorbent assay (ELISA; Labmaster, Turku, Finland). The indirect immunofluorescence method used as antigen commercially available composite rat liver, kidney, and mouse stomach sections (Biodiagnostics, United Kingdom) pretreated with a $0 \cdot 1 \mathrm{mg} / \mathrm{ml}$ aqueous solution of gliadin (Sigma, United Kingdom). ${ }^{11}$ Serum samples giving a peritubular reticulin pattern on rat kidney at a titre of one in 20 or greater were considered positive for the antibody. Results are expressed in arbitrary units (AU). The normal reference range used in our laboratory for gliadin IgA and IgG was 0-100 AU.

Endomysial antibodies were detected by indirect immunofluorescence by using commercially available sections of monkey oesophagus as antigen (Biodiagnostics). IgG and IgA specific for the endomysial lining of myofibrils were identified by their reticulinlike staining pattern of smooth muscle bundles. ${ }^{6}$ Sera containing this antibody in either immunoglobulin 
class at a titre of one in 20 or greater were considered positive. Antibodies to jejunum (IgG and $\operatorname{IgA}$ ) were detected by indirect immunofluorescence with sections of black hooded rat jejunum as antigen. Sera producing elongated villous fluorescence underlying the epithelial and cryptal basement membrane ${ }^{8}$ at a titre of one in 20 or over were considered positive. The presence of IgA 1 and $\operatorname{IgA} 2$ antibodies to gliadin, endomysium, and jejunum was also determined by indirect immunofluorescence. Pretreated gliadin composite tissue, monkey oesophagus, and rat jejunal sections were incubated with patients' sera at dilutions of one in five, one in 10, and one in 20 and then probed with fluorescein conjugated sheep antihuman $\operatorname{IgA} 1$ and IgA2 (The Binding Site, Birmingham, United Kingdom) at optimum dilution. Sera showing positive antibody reactions at a titre of one in five or over were considered positive.

All investigations were done blind and without any knowledge of other results. The sensitivity, specificity, predictive value for a positive and negative result, and the predictive efficiency of each assay were calculated ${ }^{12}$ for each antibody in relation to a clinical diagnosis or coeliac disease. The sensitivity was defined as the frequency of a positive antibody result in patients with the disease and specificity as the frequency of a negative antibody result in patients without the disease. The predictive value of a positive result indicates the proportion of patients with a positive antibody result who had coeliac disease, whereas the predictive value of a negative result indicates the proportion of patients with a negative antibody result who did not have the disease. The predictive efficiency of a test indicates the percentage of patients correctly classified by the test.

\begin{tabular}{lc} 
Diagnosis & $\begin{array}{c}\text { No of } \\
\text { patients }\end{array}$ \\
\hline $\begin{array}{l}\text { Coeliac disease } \\
\text { Definite }\end{array}$ & 28 \\
$\quad$ Probable & 28 \\
$\begin{array}{l}\text { Non-coeliac disease } \\
\text { Other gastrointestinal } \\
\text { diseases: }\end{array}$ & 68 \\
$\quad$ Ulcerative colitis & 4 \\
Abnormal biopsy & \\
$\quad$ result & 2 \\
Irritable bowel & \\
$\quad$ syndrome & 1 \\
Miscellaneous diseases: & \\
Iron deficiency & \\
anaemia & 6 \\
$\quad$ Hypothyroidism & 3 \\
Pernicious anaemia & 2 \\
Polyarthritis & 1 \\
No diagnosis & 49 \\
\hline
\end{tabular}

^By European Society of Paediatric Gastroenterology and Nutrition criteria. coeliac disease. These patients all had characteristic jejunal mucosa and showed clinical improvement after the introduction of a gluten free diet. Five of these patients did not have subtotal villous atrophy and therefore did not strictly fulfil the revised diagnostic criteria, which require a flat small intestinal mucosa. However, these patients were all thought to have coeliac disease by their consultant physician. A further seven patients were classified as having other gastrointestinal disease; two of these patients had partial villous atrophy but did not respond to a gluten free diet, four had ulcerative colitis, and one irritable bowel syndrome. One patient with ulcerative colitis and the patient with irritable bowel syndrome had partial villous atrophy. The remainder of the patients had a range of miscellaneous diseases or had no disease diagnosed at the time of review (table I). These patients all had normal results of jejunal biopsies.

Table II shows the prevalence of antibody to gliadin, endomysium, and jejunum in all the patients. Only gliadin IgA detected by ELISA was found in all patients with coeliac disease and in none without the disease. Gliadin IgA detected by immunofluoresience was found in $75 \%$ of patients with coeliac disease whereas endomysial IgA was found in $89 \%$ of patients with coeliac disease and in none of the patients without the disease. Jejunal IgA was found in $75 \%$ of the patients with coeliac disease and none of those without the disease. IgG antibodies were less prevalent than IgA class antibodies in the patients with coeliac disease but more prevalent in patients without coeliac disease. Detection of IgG or IgA antibodies, or both, showed a high sensitivity for coeliac disease. However, our high rate of false positive results in detecting IgG makes this method impractical as a screening test. IgA subtyping did not improve the sensitivity or specificity. Only IgAl antibody was detected in these patients, and this was at much lower titre than either IgG or IgA class antibody.

Table III shows the sensitivity, specificity, predictive value of a positive and negative test result, and the predictive efficiency of the assays in the patients with coeliac disease. Detection of gliadin IgA by ELISA had the highest sensitivity and specificity for a diagnosis of coeliac disease combined with the highest predictive value of a positive or negative test and predictive efficiency, all values being $100 \%$. The endomysial IgA gave slightly lower predictive value figures with the predictive efficiency being $97 \%$. In all tests the predictive values of IgG antibodies were much lower than for the corresponding IgA antibodies.

Twenty eight of 96 patients were classified as having

TABLE II - Number (percentage) of patients with antibodies to gliadin, endomysium, and jejunum

\begin{tabular}{|c|c|c|c|c|c|c|c|c|c|c|c|c|}
\hline & \multicolumn{3}{|c|}{$\begin{array}{l}\text { Gliadin by indirect } \\
\text { immunofluorescence }\end{array}$} & \multicolumn{3}{|c|}{ Gliadin by ELISA } & \multicolumn{3}{|c|}{ Endomysium } & \multicolumn{3}{|c|}{ Jejunum } \\
\hline & $\operatorname{IgG} / \operatorname{Ig} A$ & $\mathrm{IgG}$ & $\operatorname{IgA}$ & IgG/IgA & $\mathrm{IgG}$ & $\operatorname{Ig} A$ & $\operatorname{IgG} / \operatorname{IgA}$ & IgG & $\operatorname{IgA}$ & $\operatorname{IgG} / \operatorname{IgA}$ & IgG & $\operatorname{Ig} A$ \\
\hline Coeliac disease $(n=28)$ & $25(89)$ & $21(75)$ & $21(75)$ & $28(100)$ & $16(57)$ & $28(100)$ & $\begin{array}{r}26(93) \\
1(14)\end{array}$ & $\begin{array}{r}11(39) \\
1(14)\end{array}$ & $25(89)$ & $24(86)$ & $15(54)$ & $21(75)$ \\
\hline Others $^{\star}(n=61)$ & $4(7)$ & $4(7)$ & & $9(15)$ & $9(15)$ & & & & & $5(8)$ & $5(8)$ & \\
\hline
\end{tabular}

^Includes patients with miscellaneous diseases and those with no definite clinical diagnosis.

TABLE III-Predictive values (as a percentage) of presence of antibodies to gliadin, endomysium, and jejunum for coeliac disease

\begin{tabular}{|c|c|c|c|c|c|c|}
\hline Antibody & Ig class & Sensitivity & Specificity & $\begin{array}{l}\text { Predictive } \\
\text { value of } \\
\text { positive } \\
\text { test result }\end{array}$ & $\begin{array}{l}\text { Predictive } \\
\text { value of } \\
\text { negative } \\
\text { test result }\end{array}$ & $\begin{array}{l}\text { Predictive } \\
\text { efficiency }\end{array}$ \\
\hline \multirow{2}{*}{ Gliadin (immunofluorescence): } & IgG & 75 & 94 & 84 & 90 & 89 \\
\hline & IgA & 75 & 100 & 100 & 91 & 93 \\
\hline \multirow{2}{*}{ Gliadin (ELISA): } & $\operatorname{IgG}$ & 57 & 87 & 64 & 83 & 78 \\
\hline & IgA & 100 & 100 & 100 & 100 & 100 \\
\hline \multirow{2}{*}{ Endomysium: } & IgG & 39 & 99 & 92 & 80 & 81 \\
\hline & $\operatorname{IgA}$ & 89 & 100 & 100 & 96 & 97 \\
\hline \multirow{2}{*}{ Jejunum: } & $\mathrm{IgG}$ & 54 & 93 & 75 & 83 & 81 \\
\hline & $\operatorname{Ig} A$ & 75 & 100 & 100 & 91 & 93 \\
\hline
\end{tabular}

tests including gliadin IgA by ELISA and endomysial and jejunal IgA, ${ }^{813} 14$ the sensitivities and specificities in other studies have been much less. This variability partly results from differences in types of assay or method $^{15-17}$ and partly from the degree of selection of the populations studied ${ }^{18-20}-$ for example, patients with coeliac disease studied may or may not have already been taking a gluten free diet, which would affect their antibody titres. ${ }^{16}$

A screening test used in a population with a low prevalence of a condition will show a much lower positive predictive value than if used in a population with a higher prevalence. ${ }^{12}$ False high or low percep- 
tions of the value of screening tests may arise from failure to take the effects of these factors fully into account. Our values for the performance of the tests were obtained in a high prevalence group. This undoubtedly accounts for the high performance we have described for some of our tests.

It is presently considered that coeliac disease cannot be diagnosed on the basis of associated antibodies alone because of the occasional false positive or false negative results. ${ }^{3}$ Nevertheless, detection of such antibodies is of considerable value in screening for the condition,,$^{2.3}$ and, as we have shown, particularly in patients thought suitable for jejunal biopsy after appropriate clinical assessment and simple blood tests.

Testing for coeliac disease associated antibodies, particularly gliadin IgA by ELISA, promises to simplify and make more efficient the selection of patients for jejunal biopsy and perhaps in the not too distant future may allow the condition to be diagnosed with confidence without the need for biopsy. However, a similar high performance of this or some other assay would need to be shown in a less selected population before biopsy becomes unnecessary.

1 McNeish AS, Harms HK, Rey J Shmerling DH, Visakord JK, WakerSmith JA. The diagnosis of coeliac disease. A commentary on the curren practices of members of the European Society for Paediatric Gastroenterology and Nutrition (ESPGAN). Arch Dis Child 1979;54:783-6.

2 Guandalini S, Ventura A, Ansaldi N, Giunta AM, Greco L, Lazzari R, et al. Diagnosis of coeliac disease: time for change? Arch Dis Child 1989;64: $1320-5$

3 Walker-Smith JA, Guandalini S, Schmitz J, Shmerling Visakorpi JK. Revised criteria for diagnosis of coeliac disease. Arch Dis Child 1990;65:909-11.

4 Diagnosis of coeliac disease. Lancet 1991:337:590.

5 Dias J, Unsworth DJ, Walker-Smith JA. Antigliadin and antireticulin antibodies in screening for coeliac disease. Lancet 1987;ii: 157-8.

Hällström $\mathrm{O}$. Comparison of IgA-class reticulin and endomysial antibodies in coeliac disease and dermatitis herpetiformis. Gut 1989;30:1225-32.
7 Chorzelski TP, Beutner EH, Sulej J, Chorzewska H, Jablonska S, Kumar V, et al. IgA anti-endomysium antibody. A new immunological marker of dermatitis herpetiformis and coeliac disease. $B r \mathcal{Y}$ Dermatol 1984;111: $395-402$

8 Kárpáti S, Bürgin-Wolff A, Krieg T, Meurer $M$, Stolz W, Braun-Falco $O$. Binding to human jejunum of serum $\operatorname{IgA}$ antibody from children with coeliac disease. Lancet 1990;336:1335-8.

9 Elewaut A, Dacremont G, Robberecht E, Leroy J, De Baets MH. IgA isotyping of gliadin antibodies. A possible clue for a less invasive diagnosis of coeliac disease. Clin Chim Acta 1989;183:285-94.

10 Volta U, Molinaro N, Fratangelo D, Bianchi FB. IgA subclass antibodies to gliadin in serum and intestinal juice of patients with coeliac disease. Clin Exp Immunol 1990;80:192-5.

11 Unsworth DJ, Manuel PD, Walker-Smith JA, Campbell JA, Johnston GD, Holborow EJ. New immunofluorescent blood test for gluten sensitivity. Arch Dis Child 1981;56:864-8.

12 Gallen RS. Use of predictive value theory in clinical immunology. In: Rose NR, Friedman H, Fahey JL, eds. Manual of clinical laboratory immunology. 3rd ed. Washington: American Society for Microbiology, 1986:966-71.

13 Kumar V, Lerner A, Valeski JE, Beutner EH, Chorzelski TP, Rossi T. Endomysial antibodies in the diagnosis of celiac disease and the effect of gluten on antibody titers. Immunol Invest 1989;18:533-44.

14 Ascher H, Lanner A, Kristiansson B. A new laboratory kit for anti-gliadin IgA at diagnosis and follow-up of childhood celiac disease. $\mathcal{F}$ Pediatr Gastroenterol Nutr 1990;10:443-50.

15 Kelly J, O'Farrelly C, Rees JP, Feighery C, Weir DG. Humoral response to alpha gliadin as a serological screening test for coeliac disease. Arch Dis Child 1987;62:469-73.

16 Bürgin-Wolff A, Berger R, Gaze H, Huber H, Lentze MJ, Nussle D. IgG, IgA and IgE gliadin antibody determinations as a screening test for untreated coeliac disease in children, a multicentre study. Eur $\mathcal{f}$ Pediatr 1989;148:496-502.

17 Watson RGP, McMillan SA, Dolan C, O'Farrelly C, Cuthbert RJG, Haire M, et al. Gliadin antibody detection in gluten enteropathy. Ulster Med $\mathcal{f}$ 1986;55:160-4

18 Koletzko S, Bürgin-Wolff A, Koletzko B, Knapp M, Gruneklee D, Hertz G, et al. Prevalence of coeliac disease in diabetic children and adolescents. A multicentre study. Eur 7 Pediatr 1988;148:113-7.

19 Grodzinsky E, Hed J, Lieden G, Siorgren F, Strom M. Presence of IgA and IgG antigliadin antibodies in healthy adults as measured by micro-ELISA. IgG antigliadin antibodies in healthy adults as measured by micro-ELISA. Effect of various cutoff levels on specificity and sensitivity when
coeliac disease. Int Arch Allergy Appl Immunol 1990;92:119-23.

20 Scott H, Fausa O, Ek J, Valnes K, Blystad L, Brandtzaeg P. Measurements of serum IgA and $\operatorname{IgG}$ activities to dietary antigens. A prospective study of the diagnostic usefulness in adult coeliac disease. Scand $\mathcal{F}$ Gastroenterol 1990;25 $287-92$

(Accepted 30 August 1991)
Department of Clinical

Health, London WC1 1EH Lyn S Chitty, MRCOG, research fellow

\section{Luton and Dunstable} Hospital, Luton,

Bedfordshire

Gaye H Hunt, DMU, superintendent radiographer Jennifer Moore, DMU, senior radiographer

Michael O Lobb, FRCOG, consultant obstetrician

Correspondence to: Dr Lyn S Chitty, Paediatric Research Unit, Guy's Tower, London SE1 9RT.

BMf 1991;303:1165-9

\title{
Effectiveness of routine ultrasonography in detecting fetal structural abnormalities in a low risk population
}

\author{
Lyn S Chitty, Gaye H Hunt, Jennifer Moore, Michael O Lobb
}

\section{Abstract}

Objective-To review the efficacy of routine prenatal ultrasonography for detecting fetal structural abnormalities.

Design-Retrospective study of the ultrasonographic findings and outcome of all pregnancies in women scanned in 1988-9.

Setting-Maternity ultrasonography department of a district general hospital.

Subjects -8785 fetuses.

Main outcome measures-Correlation of prenatal ultrasonographic findings with outcome in the neonate.

Results - 8733 babies were born during 1988-9, and 52 pregnancies were terminated after a fetal malformation was identified. $8432(95 \%)$ of the fetuses were examined by ultrasonography in the second trimester. 130 fetuses $(1 \cdot 5 \%)$ were found to have an abnormality at birth or after termination of pregnancy, 125 of which had been examined in the second trimester. In 93 cases the abnormality was detected before 24 weeks (sensitivity $74.4 \%$, 95\% confidence interval to $66 \cdot 7 \%$ to $82 \cdot 1 \%$. Two false positive diagnoses occurred, in both cases the pregnancies were not terminated and apparently normal infants were born. This gives a specificity of $\mathbf{9 9 . 9 8 \%}(\mathbf{9 9 . 9} \%$ to $99.99 \%)$. The positive predictive value of ultrasonography in the second trimester was $97.9 \%$ (92.6\% to $99.7 \%)$. Of the 125 abnormalities, 87 were lethal or severely disabling; 72 of the 87 were detected by the routine screening programme (sensitivity $82 \cdot 8 \%, 73 \cdot 2 \%$ to $90 \cdot 0 \%$ ).

Conclusion-Routine fetal examination by ultrasonography in a low risk population detects many fetal structural abnormalities but can present several dilemmas in counselling.

\section{Introduction}

Much evidence exists to suggest that routine ultrasonography in the second trimester improves the diagnosis of multiple pregnancies and the estimation of the expected date of delivery. But there are few reports of its use in screening for congenital malformations, such malformations occur in $2-3 \%$ of all infants and account for about a quarter of all perinatal deaths. ${ }^{12}$ Prenatal ultrasonography can detect many fetal malformations, ${ }^{3}$ about $90 \%$ of which occur in fetuses born to parents with no recognisable risk factors.

Persson and Kullander reported that in their routine screening programme 50 anomalies were detected but only 12 were detected early enough to allow termination of pregnancy. ${ }^{4}$ However, they do not state the number of abnormalities that were not diagnosed prenatally. Campbell and Smith reported detection of $85 \%$ of major anomalies and one false positive diagnosis of hydrocephalus in a routine screening programme, but the study was based in a unit with a particular interest

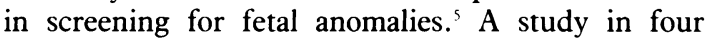
Belgian hospitals found that one third to one half of all 